\title{
Prevalence and severity of distal symmetrical polyneuropathy among patients with type 2 diabetes mellitus in Zaria, Nigeria
}

\author{
Kaoje YS ${ }^{1}$, Bello F ${ }^{2}$, Bansi IK ${ }^{3}$, Bakari AG ${ }^{4}$, Yakubu IM ${ }^{5 *}$ and Lawal $\mathrm{Y}^{6}$ \\ ${ }^{1}$ Consultant Endocrinologist, Department of Medical Services, CBN Clinic Abuja, Nigeria \\ ${ }^{2}$ Consultant Endocrinologist, Endocrinology Unit, Department of Medicine, Ahmadu Bello University Teaching Hospital, Shika-Zaria, Nigeria \\ ${ }^{3}$ Senior Registrar, Endocrinology Unit, Department of Medicine, Ahmadu Bello University Teaching Hospital, Shika-Zaria, Nigeria \\ ${ }^{4}$ Consultant Endocrinologist, Endocrinology Unit, Department of Medicine, Ahmadu Bello University Teaching Hospital, Shika-Zaria, Nigeria \\ ${ }^{5}$ PhD Student in Public Health at Texila American University, Department of Medical Services, CBN Clinic Abuja, Nigeria \\ ${ }^{6}$ Consultant Endocrinologist, Department of Medicine, Federal Medical Center, Azare, Bauchi State, Nigeria
}

\begin{abstract}
Background: Distal symmetrical polyneuropathy (DSPN) is among the common and serious complications of diabetes mellitus (DM). However, there is paucity of data on its prevalence and severity in Northern Nigeria. The study was, therefore, aimed to determine the prevalence and severity of DSPN among type 2 DM subjects at Ahmadu Bello University Teaching Hospital (ABUTH), Zaria, Nigeria.

Method: This study was a cross-sectional comparative study of 330 type 2 diabetes subjects presenting consecutively at the endocrine clinic of ABUTH, Zaria and 165 healthy controls randomly selected from a community in Zaria. Socio-demographic data were obtained using an interviewer-administered questionnaire and subjects were physically examined. Biothesiometry and the United Kingdom Screening Test (UKST) were used to assess peripheral neuropathy in both cases and controls. Data was analysed with SPSS version-17 using Chi-square analysis and Student t-test.
\end{abstract}

Results: The mean \pm SD age of the DM subjects was $49.60 \pm 9.81$ years while that of the controls was $49.93 \pm 10.09$ years ( $p=0.73$ ). The prevalence of DSPN was $39.7 \%$ among type-2 diabetes patients and $6.1 \%$ among controls. Moderate and severe neuropathy were present in $30.3 \%$ and $6.0 \%$ of the diabetic subjects respectively.

Conclusion: DSPN is commoner among people with diabetes mellitus when compared to healthy controls with a large proportion of subjects presenting with moderate severity. It is recommended that efforts be made to screen for DSPN among diabetes patients using simple and sensitive methods.

\section{Introduction}

Diabetes mellitus (DM) is a complex metabolic disorder characterized by persistent hyperglycemia resulting from defects in insulin secretion, insulin action or both [1]. While atherosclerotic vascular disease in diabetes (macrovascular complication) is associated with premature mortality, microvascular complications namely diabetic retinopathy, nephropathy and neuropathy are associated with considerable morbidity. This trend leads to significant economic and social costs both from health care services and through loss of productivity [1].

Peripheral neuropathy is a general term used to describe disorders of the peripheral nerves. Although DM is thought to be the commonest cause of peripheral neuropathy, there are so many other causes including autoimmune disorders, inherited neuropathies, drugs, toxins, infections, trauma etc.

Diabetic Neuropathy (DN) is defined as somatic and/or autonomic neuropathy that is attributed solely to DM [2]. Rochester Diabetes study showed that up to $10 \%$ of peripheral neuropathy in diabetic patients was due to causes other than diabetes [3]. Diabetic Sensorimotor Polyneuropathy (DSPN), a type of diabetic neuropathy (DN) has several names e.g. Distal Symmetrical Polyneuropathy, Distal Symmetrical Peripheral Neuropathy $[3,4]$.

DPN presents in various ways and is generally classified as focal or generalized neuropathies. Diffuse neuropathies are more common and include DSPN, autonomic neuropathies, acute painful neuropathy and hyperglycaemic neuropathy. The focal neuropathies are less common and usually self-limiting with variable duration; they include thoracolumbar radiculoneuropathy (DTLRN), lumbosacral radiculoplexus neuropathy (DLSRPN), also known as diabetic amyotrophy, and entrapment neuropathy $[5,6]$.

DSPN is the commonest type of DN and is often considered synonymous with DN. It often presents insidiously with symptoms

${ }^{*}$ Correspondence to: Idris Muhammad Yakubu, PhD Student in Public Health at Texila American University, Department of Medical Services, CBN Clinic Abuja, Nigeria, E-mail: yidris2000@yahoo.co.uk

Key words: diabetes mellitus, distal symmetrical polyneuropathy, biothesiometry, United Kingdom screening test, Zaria

Received: January 03, 2020; Accepted: January 23, 2020; Published: January 28,2020 
initially in the lower limbs. Symptoms include dysaesthesia, unprovoked pain, and hyperaesthesia. Symptoms are usually worse at night and can lead to mood disorders like anxiety and depression. However, a lot of patients may be asymptomatic with foot ulcer being the first presentation [7].

According to the American Diabetes Association (ADA), DN should not be diagnosed using a symptom, sign or test in isolation, but a minimum of two abnormalities (from symptoms, signs, nerve conduction studies, quantitative sensory testing or quantitative autonomic tests). In clinical trials and epidemiological studies, either quantitative tests or electrophysiology should be included [8].

Clinical practice guidelines recommend annual screening for neuropathy in all patients with DM as part of routine assessment for complications. This screening offers the patient the opportunity to take actions like improving glycaemic control to reduce morbidity [2].

There are various methods of screening for DSPN. They include neurological history, neurological examination, composite scoring systems, quantitative sensory testing, nerve conduction studies (NCS), and novel methods like nerve biopsy, skin biopsy, corneal confocal microscopy, and nerve axon reflex/flare response [2].

United Kingdom Screening Test (UKST) is the most widely used and accepted scoring system for DSPN. It is a simple, reproducible, and reliable test for rapid screening of DSPN. It has been validated in Nigeria with good results. It is quantitative and could be used to grade the severity of DSPN. It is a useful substitute for NCS especially in resource-poor settings [9].

The Biothesiometer is an instrument used to quantify vibration perception threshold (VPT). A threshold of $>25$ volts is considered high risk for foot ulcer with the risk increasing up to seven times. Studies have shown consistent correlation between VPT measures and sural nerve conduction velocity. VPT is also said to be a sensitive measure of mild or subclinical neuropathy [10].

This study intends to assess the frequency and severity of DSPN. This is in view of the fact that DSPN is the leading cause of diabetic foot disease worldwide. With the risk of amputation in diabetic patients 25 times more than in people without diabetes mellitus [1]. Early detection would allow for the institution of measures to prevent this dreaded complication.

\section{Materials and methods}

This is a descriptive cross-sectional comparative study conducted over six months in 2016 involving persons with type 2 diabetes mellitus and non-diabetic subjects in Zaria. A total of 330 persons with type 2 diabetes, aged 18-64 years old, who gave informed consent were recruited consecutively as they presented to the endocrinology clinic or medical wards at ABUTH, Zaria. Also, 165 non-diabetic individuals, aged 18-64 years old, who gave informed consent were recruited as controls in communities in Zaria city. The exclusion criteria included subjects with history of conditions known to cause peripheral neuropathy e.g. leprosy, HIV, Guillain-Barre syndrome; those on drugs known to cause peripheral neuropathy e.g. nitrofurantoin, antituberculosis drugs, anti-cancer drugs, anti-retrovirals, phenytoin, metronidazole [11] lower limb amputees; people with history of stroke, and comatose individuals.

Data was collected using a pre-tested interviewer-administered questionnaire. The questionnaire was pre-tested on 10 patients who were randomly selected using simple random sampling technique at the endocrine clinic of ABUTH. Each subject was interviewed and examined. History included sociodemographic and medical history while physical examination included weight, height, waist circumference, blood pressure, fundoscopy, and neurological examination. Screening DSPN was done using UKST and Biothesiometry.

For the purpose of this study, an individual was said to have DSPN if both UKST and biothesiometry were abnormal. Using biothesiometry, a subject with a threshold of $>25$ volts in both feet was considered to have peripheral neuropathy $[10,12-14]$. For the UKST, a subject was said to have peripheral neuropathy if he/she had at least moderate neuropathy disability score (NDS) of $\geq 6$ or at least mild NDS (score $\geq 3$ ) plus moderate neuropathy symptom score (NSS) of $\geq 5$ $[15,16]$. The severity of neuropathy was further assessed by grading the NDS.

Vibration sensation was tested bilaterally using a $128 \mathrm{~Hz}$ generic tuning fork placed over the apex of the big toe $[10,17]$. The ankle reflexes was examined using a Queen-square tendon hammer [10]. Temperature sensation was measured using a tuning fork placed in a beaker containing ice water for one minute. The test was done over the dorsum of the foot or pulp of the hallux. With the eyes closed, the patient was asked to describe the stimulus. The test was considered abnormal if the subject felt the cold tuning fork as warm or he was unable to describe the feeling.8 Pain sensation was tested using a disposable pin sharp enough to cause a painful sensation. The pin was applied proximal to the big toe nail just enough to depress the skin [10].

A digital biothesiometer (Vibrometer Diabetic Foot Care India) comprising a VPT probe, a user manual, digital voltage display, and voltage adjustable knob was used to measure VPT $[17,18]$. A single site on each foot was used since studies have shown no significant difference between single site and multiple site testing [19]. A single site was preferred considering the fact that the shorter the examination time, the more accurate the results obtained since subject's attention was needed [19].

Ethical approval for the study was obtained from the ABUTH Health Research and Ethics Committee.

Statistical package for social sciences (SPSS) version 17.0 was used to analyse all data. Quantitative variables like age, weight, height etc. were summarized as mean and standard deviation. Student $\mathrm{t}$-test was used to compare quantitative variables between cases and controls while Chi-square was used to compare qualitative variables between cases and controls. A p-value of $<0.05$ was considered statistically significant.

\section{Results}

A total of 495 subjects participated in the study, of which 330 had diabetes mellitus and the remaining 165 were controls. The mean age of the subjects with diabetes mellitus was $49.60 \pm 9.81$ years, while that of the control was $49.93 \pm 10.09$ years $(\mathrm{p}=0.727)$. The male respondents among the cases were $100(30.3 \%)$ and $63(38.2 \%)$ in the control group. The female respondents were $230(69.7 \%)$ among the cases and 102 (61.8\%) among the control ( $\mathrm{p}=0.0782)$ as shown in Table 1 .

The overall prevalence of DSPN was found to be higher among subjects with diabetes than controls ( $39.7 \%$ vs. $6.1 \%)$ as shown in Table 2. Twenty-nine subjects with diabetes $(8.8 \%)$ had mild neuropathy, $100(30.3 \%)$ had moderate neuropathy, and $20(6.1 \%)$ had severe neuropathy (Table 3). 
Table 1. Socio-demographic characteristics of subjects

\begin{tabular}{|c|c|c|}
\hline Variable & Cases N (\%) & Control N (\%) \\
\hline Age (years), mean \pm SD & $49.60 \pm 9.81$ & $49.93 \pm 10.09$ \\
\hline $18-25$ & $1(0.3 \%)$ & $1(0.6 \%)$ \\
\hline $26-35$ & $41(12.4 \%)$ & $21(12.7 \%)$ \\
\hline $36-45$ & $74(22.4 \%)$ & $36(21.8 \%)$ \\
\hline $46-55$ & $101(30.6)$ & $47(28.5 \%)$ \\
\hline $56-65$ & $113(34.2 \%)$ & $60(36.4 \%)$ \\
\hline \multicolumn{3}{|l|}{ Gender } \\
\hline Male & $100(30.3 \%)$ & $63(38.2 \%)$ \\
\hline Female & $230(69.7 \%)$ & $102(61.8 \%)$ \\
\hline \multicolumn{3}{|l|}{ Marital status } \\
\hline Single & $11(3.3 \%)$ & $3(1.8 \%)$ \\
\hline Married & $265(80.3 \%)$ & $162(98.2 \%)$ \\
\hline Divorced & $5(1.5 \%)$ & $0(0 \%)$ \\
\hline Widowed & $49(14.8 \%)$ & $0(0 \%)$ \\
\hline \multicolumn{3}{|l|}{ Education } \\
\hline Primary & $66(20 \%)$ & $17(10.3 \%)$ \\
\hline Secondary & $63(19.1 \%)$ & $16(9.7 \%)$ \\
\hline Tertiary & $71(21.5 \%)$ & $2(1.2 \%)$ \\
\hline Non-formal & $130(39.4 \%)$ & $130(78.8 \%)$ \\
\hline \multicolumn{3}{|l|}{ Ethnicity } \\
\hline Hausa & $199(60.3 \%)$ & $164(99.4 \%)$ \\
\hline Fulani & $26(7.9 \%)$ & $1(0.6 \%)$ \\
\hline Yoruba & $18(5.5 \%)$ & $0(0 \%)$ \\
\hline Igbo & $17(5.2 \%)$ & $0(0 \%)$ \\
\hline Others & $70(21.2 \%)$ & $0(0 \%)$ \\
\hline \multicolumn{3}{|l|}{ Occupation } \\
\hline Civil servant & $83(25.2 \%)$ & $1(0.6 \%)$ \\
\hline Business & $101(30.6 \%)$ & $56(33.9 \%)$ \\
\hline Farmer & $9(2.7 \%)$ & $44(26.7 \%)$ \\
\hline Housewife & $109(33 \%)$ & $50(30.3 \%)$ \\
\hline Others & $28(8.5 \%)$ & $14(8.5 \%)$ \\
\hline
\end{tabular}

Legend: SD-standard deviation, N-number

Table 2. Prevalence of diabetic sensorimotor polyneuropathy

\begin{tabular}{|c|c|c|c|c|}
\hline Method & $\begin{array}{c}\text { Diabetic (\%) } \\
\mathbf{N = 3 3 0}\end{array}$ & $\begin{array}{c}\text { Control (\%) } \\
\mathbf{N = 1 6 5}\end{array}$ & $\mathbf{X}^{2}$ & P value \\
\hline Biothesiometry & & & 60.819 & $<\mathbf{0 . 0 0 0 1}$ \\
\hline Absent & $199(60.3 \%)$ & $155(93.9 \%)$ & & \\
\hline Present & $131(39.7 \%)$ & $10(6.1 \%)$ & & $<1.148$ \\
\hline UKST & & & & $<\mathbf{0 . 0 0 0 1}$ \\
\hline Absent & $187(56.7 \%)$ & $155(93.9 \%)$ & & \\
\hline Present & $143(43.3 \%)$ & $10(6.1 \%)$ & & $<\mathbf{0 . 0 0 0 1}$ \\
\hline Combined & & & 60.819 & \\
\hline Absent & $199(60.3 \%)$ & $155(93.9 \%)$ & & \\
\hline Present & $131(39.7 \%)$ & $10(6.1 \%)$ & & \\
\hline
\end{tabular}

Abbreviations: $\mathrm{X}^{2}$ (chi-square), UKST (United Kingdom Screening Test), $p<0.05$ is statistically significant

Table 3. Severity of diabetic sensorimotor polyneuropathy

\begin{tabular}{|c|c|c|c|c|}
\hline Score & NDS & Diabetics & Control & Total \\
\hline $\mathbf{0 - 2}$ & Normal & $181(54.8 \%)$ & $155(93.9 \%)$ & $\mathbf{3 3 6}$ \\
\hline $\mathbf{3 - 5}$ & Mild & $29(8.8 \%)$ & $0(0 \%)$ & $\mathbf{2 9}$ \\
\hline $\mathbf{6 - 8}$ & Moderate & $100(30.3 \%)$ & $8(4.8 \%)$ & $\mathbf{1 0 8}$ \\
\hline $\mathbf{9 - 1 0}$ & Severe & $20(6.1 \%)$ & $2(1.2 \%)$ & $\mathbf{2 2}$ \\
\hline & & $\mathbf{3 3 0}$ & $\mathbf{1 6 5}$ & $\mathbf{4 9 5}$ \\
\hline
\end{tabular}

NDS: neuropathy disability score

\section{Discussion}

The mean age of the cases was $49.60 \pm 9.81$ years reflecting the high prevalence of diabetes in this age group [1]. This result was similar to the findings in some local and international studies on diabetic peripheral neuropathy $[16,20,21]$. The presence of more females in this study (69.7\%) is similar to observations made among diabetic subjects in Ibadan, Jos and Kano [16,20,22] Similarly, studies among people with diabetes in Dubai and Portugal had more females (67\% and $60.2 \%$ respectively) $[23,24]$. This may be explained by the fact that females have better health seeking behaviour than their male counterparts [25]. Also, in most African countries, men are often the breadwinners of their families, hence, having little time for their health.

The overall prevalence of DSPN was found to be $39.7 \%$ while the prevalence of peripheral neuropathy among the non-diabetic subjects was much lower $(6.1 \%)$. This compares well with the prevalence of DSPN reported by Ugoya et al. (40.4\%) in Jos which used a different screening tool [22]. However, the prevalence of Diabetic Peripheral Neuropathy (DPN) in other parts of Nigeria was put at 59.2\% according to a multicentre study by Chinenye et al. a study in Ibadan found a prevalence of $71.1 \%$; while a study in Kano reported a lower prevalence of $31.2 \%$. [16,26].

Tesfaye et al. found an estimated prevalence of DPN in Africa of $4-48 \%$ [27]. Studies in Portugal, Iran, Saudi Arabia, and Sri Lanka revealed a prevalence of DPN of $32.2 \%, 51.7 \%, 19.9 \%$, and $48.1 \%$ respectively $[21,24,28,29]$.

The prevalence rate in various studies show considerable variation due to variations in study design, diagnostic methods (i.e. symptoms only, signs and symptoms, electromyography / nerve conduction studies (EMG/NCS), quantitative sensory testing (QST) or composite parameters), the examination of patients at different stages in the natural history of diabetes, or in the definition of DPN.

Using the neuropathy disability score (NDS), among the study subjects, $30 \%$ had moderate neuropathy and $6 \%$ had severe neuropathy. Ibrahim et al. in Kano, North-western Nigeria, reported a prevalence of $26.2 \%$ and $3.8 \%$ for moderate and severe neuropathy respectively using the NDS [16]. Similarly, Ugoya et al. in a study in Jos, North-central Nigeria, using the Dyck grading system to classify DPN reported $11.6 \%$ and $17.4 \%$ of the subjects to have grade 2 and 3 neuropathy respectively [20].

A study in Uganda also classified DPN severity using NDS with prevalence of moderate and severe neuropathy of $16 \%$ and $5 \%$ respectively [30]. Bansal et al. in India classified DPN using biothesiometry and reported moderate and severe neuropathy in $14.5 \%$ and $6.6 \%$ of the subjects respectively [31]. A community based study in the United Kingdom reported a prevalence of moderate and severe DPN of $13.8 \%$ and $10 \%$ respectively using the Toronto Clinical Scoring System (TCSS) [32]. These differences in severity are likely due to variations in patient characteristics and the use of different methods of assessment.

Our study was not without limitations. These included nonavailability of nerve conduction studies and inability to exclude some other causes of peripheral neuropathy e.g. toxins, vitamin (B1, B6, B12) deficiency and genetic causes. Therefore, there is a need for multi-centre studies with similar patient characteristics, diagnostic methods, and diagnostic criteria so as to elucidate the true burden of this condition.

\section{Conclusion}

DSPN is commoner among people with diabetes mellitus when compared to healthy controls with a large proportion of subjects presenting with moderate severity. Screening for the early detection 
and treatment of DSPN in people living with type 2 DM would go a long way in preventing pain and disability (from amputation) as well as improving the quality of life.

\section{Declaration}

The authors declare that they have no competing interest.

\section{References}

1. International Diabetes Federation (2013) IDF Diabetes Atlas. $6^{\text {th }}$ ed. Guariguata L, Nolan T, Beagley J, Linnenkamp UJ, editors. IDF.

2. Tesfaye S, Boulton AJM, Dyck PJ, Freeman R, Horowitz M, et al. (2010) Diabetic neuropathies: update on definitions, diagnostic criteria, estimation of severity, and treatments. Diabetes Care 33: 2285-2293.

3. Dyck PJ, Karnes J, O'Brien P, Litchy W, Low P, et al. (1992) The Rochester diabetic neuropathy study: reassesment of tests and criteria for diagnosis and staged severity. Neurology 42: 1164-1170.

4. Nathan DM (1993) Long-term complications of diabetes mellitus. $N$ Engl J Med 328: 1676-1685. [Crossref]

5. Thomas PK (1997) Classification, differential diagnosis, and staging of diabetic peripheral neuropathy. Diabetes 46: 54-57.

6. Bhatia R, Yadav R (2008) Everyday practice?: diabetes mellitus approach to a patient with diabetic neuropathy. Natl Med J India 21: 236-242.

7. Llewelyn JG (2003) The diabetic neuropathies: types, diagnosis and management. $J$ Neurol Neurosurg Psychiatry 74: 15-19.

8. Boulton JM, Malik RA, Arezzo JC, Sosenko JM (2004) diabetic somatic neuropathies. Diabetes Care 27: 1458-1486.

9. Lavery Byla, Armstrong DG, Boulton A (2004) Screening for diabetic peripheral neuropathy. Diabet Microvasc Complicat Today 1: 17-19.

10. Cornblath DR (2004) Diabetic neuropathy: diagnostic methods. Adv Stud Med 4: 650661.

11. Azhary H, Farooq MU, Bhanushali M, Majid A, Kassab MY (2010) Peripheral neuropathy: differential diagnosis and management. Am Fam Physician 81: 887-892.

12. Wu SC, Driver VR, Wrobel JS, Armstrong DG (2007) Foot ulcers in the diabetic patient, prevention and treatment. Vasc Health Risk Manag 3: 65-76. [Crossref]

13. Gin H, Rigalleau V, Baillet L, Rabemanantsoa C (2002) Comparism between monofilament, tuning fork and vibration perception test for screening patients at risk of foot complications. Diabetes Metab (Paris) 28: 457-461.

14. Armstrong DG, Lavery LA, Vela SA, Quebedeaux TL, Fleischli JG (1998) Choosing a practical screening instrument to identify patients at risk for diabetic foot ulceration. Arch Intern Med 158: 289-292.

15. Soheilykhah S, Rashidi M, Dehghan F, Shojaoddiny-Ardekani A, Rahimi-saghand S (2014) Prevalence of peripheral neuropathy in diabetic patients. Iran J Diabetes Obes 5: 107-113.
16. Ibrahim A, Owolabi LF, Borodo MM, Ogunniyi A (2015) Clinical profile of diabetic sensorimotor polyneuropathy in a tertiary hospital in Northwestern Nigeria. Niger $J$ Basic Clin Sci 12: 13-19.

17. Jayaprakash P, Bhansali A, Bhansali S, Dutta P (2011) Validation of bedside methods in evaluation of diabetic peripheral neuropathy. Indian J Med Res 133: 645-649.

18. Shakoor N, Agrawal A, Block JA (2008) Reduced lower extremity vibration perception in osteoarthritis of the knee. Arthritis Rheum 59: 117-121.

19. Armstrong DG, Hussain SK, Middleton J, YK (1998) Vibration perception threshold: are multiple sites of testing superior to single site testing on diabetic foot examination? Ostomy Wound Manag 44: 70-74.

20. Ugoya S, Echejoh G, Ugoya TA, Agaba E, Puepet FH, et al. (2006) Clinically diagnosed diabetic neuropathy? frequency, types and severity. J Natl Med Assoc 98: 1763-1766.

21. Wang DD, Bakhotmah BA, Hu FB, Ali Alzahrani H (2014) Prevalence and correlates of diabetic peripheral neuropathy in a Saudi Arabic population: A cross-sectional study. PLoS One 9: 1-8.

22. Owolabi MO, Ipadeola A, Adeleye JO (2010) Aggregate cardiovascular risk is a stronger statistical correlate of clinically evident diabetic peripheral neuropathy than HbA1c alone. J Natl Med Assoc 102: 707-712.

23. Al-kaabi JM, Maskari F Al, Zoubeidi T, Abdulle A, Shah SM, et al. (2014) Diabetes and metabolism: prevalence and determinants of peripheral neuropathy in patients with type 2 diabetes attending a tertiary care centre in the United Arab Emirates. J Diabetes Metab 5: 1-7.

24. Barbosa AP, Medina JL, Ramos EP, Barros HP (2001) Prevalence and risk factors of clinical diabetic neuropathy in a Portuguese primary health care population. Diabetes Metab 27: 496-502.

25. Thompson AE, Anisimowicz Y, Miedema B, Hogg W, Wodchis WP (2016) The influence of gender and other patient characteristics on health care-seeking behaviour?: a Qualicopc study. BMC Fam Pract 17: 1-7.

26. Chinenye S, Uloko AE, Ogbera AO, Ofoegbu EN, Fasanmade OA (2012) Profile of Nigerians with diabetes mellitus - Diabcare Nigeria study group (2008): Results of a multicentre study. Indian J Endocrinol Metab 16: 558-564.

27. Tesfaye S, Gill G (2011) Chronic diabetic complications in Africa. African J Diabetes Med 19: 4-8.

28. Rahimdel A, Afkhami-ardekani M, Souzani A, Modaresi M (2009) Prevalence of sensory neuropathy in type 2 diabetic patients in Iranian population (Yazd province). Iran J Diabetes Obes 1: 30-35.

29. Katulanda P, Ranasinghe P, Jayawardena R, Constantine GR, Sheriff MH, et al (2012) The prevalence, patterns and predictors of diabetic peripheral neuropathy in a developing country. Diabetol Metab Syndr 4: 1-8.

30. Kisozi T, Mutebi E, Kisekka M (2017) Prevalence, severity and factors associated with peripheral neuropathy among newly diagnosed diabetic patients attending Mulago hospital: a cross-sectional study. Afr Health Sci 17: 463-473. [Crossref]

31. Bansal D, Gudala K, Muthyala H, Esam HP, Nayakallu R, et al. (2014) Prevalence and risk factors of development of peripheral diabetic neuropathy in type 2 diabetes mellitus in a tertiary care setting. J Diabetes Investig 5: 714-721.

32. Davies M, Brophy S, Williams R, Taylor A (2006) The prevalence, severity, and impact of painful diabetic peripheral neuropathy in type 2 diabetes. Diabetes Care 29: 15181522 .

Copyright: (C2020 Kaoje YS. This is an open-access article distributed under the terms of the Creative Commons Attribution License, which permits unrestricted use, distribution, and reproduction in any medium, provided the original author and source are credited. 